\title{
Gestão de custos no setor açougue de uma cooperativa de consumo
}

\author{
Andréa Oliveira da Silveira \\ Pós-Graduação em Gestão de Custos pelo Centro Universitário UNINTER \\ Contadora da empresa Ipiranga Assessoria Contábil Empresarial \\ Rua Duque de Caxias, 985. Santa Maria/RS. CEP: 72505-412 \\ E-mail: andrea@ipirangacontabil.com
}

Ana Paula Meneghetti Borges Mestrado em Engenharia de Produção pela Universidade Federal de Santa Maria UFSM Contadora da Universidade Federal de Santa Maria - UFSM Rua Duque de Caxias, 985. Terreo. Centro. Santa Maria/RS. CEP: 97010-200 E-mail: apmeneghetti@yahoo.com.br

Maria Dolores Pohlmann Velasquez Mestrado em Administração pela Universidade Federal de Santa Maria - UFSM Professora do Centro Universitário Franciscano - UNIFRA Rua Silva Jardim, 1175. Conjunto III. Santa Maria/RS. CEP: 97010-491

E-mail:mdolores@ufsm.br

\section{RESUMO}

Este estudo foi desenvolvido no quarto trimestre de 2010 em uma cooperativa de consumo, setor açougue, localizada em Santa Maria/RS, Brasil. O estudo descritivo apresenta-se com abordagem quantitativa e tem como objetivo principal determinar por meio de um método de custeio específico o custo dos produtos vendidos no setor de açougue. Para determinar o custo das mercadorias compradas para revenda foi utilizado o custo médio e para alocação dos custos conjuntos aos co-produtos (produtos oriundos de uma mesma matéria-prima) foi utilizado o método do valor de mercado. Os demais custos como depreciação, manutenção, energia elétrica, materiais diversos e o restante da mão de obra que não foi incluído como custo de desossa foram rateados aos produtos pelo volume produzido. O método do custeio utilizado foi o custeio por absorção. O custo de compra dos cortes de carne ovina apresentou pouca variação entre os três meses analisados como também nos tipos de corte. Porém, no custo de compra da carne bovina foi considerada variação tanto entre os meses como nos tipos de corte. Os produtos tipos agulha, paleta, ponta de peito e osso buço bovinos e a lingüiça suína apresentaram margem bruta negativa, cabendo a entidade estudar a melhor maneira de precificar suas vendas, bem como melhorar os controles dos gastos com vistas a apurar de forma mais precisa os custos de seus produtos.

Palavras-chave: Custos Conjuntos. Açougue. Cooperativa de consumo. 
Gestão de custos no setor açougue de uma cooperativa de consumo. Andréa Oliveira da Silveira, Ana Paula Meneghetti Borges, Maria Dolores Pohlmann Velasquez

\section{ABCSTRACT}

Cooperative societies, as well as any organization, need an adequate cost accounting, because it generates information that helps in better management of costs. The research is a case study developed in the fourth quarter of 2010 in a consumer cooperative, butcher industry, located in Santa Maria / RS, Brazil. The descriptive study shows a qualitative and quantitative approach and the main purpose is to determine the cost of goods sold in the butchery industry through a specific method of funding .The cost of goods purchased for resale was used to determine the average cost and the allocation of joint costs to the co-products (products from the same raw material) used the market value method. Other costs such as depreciation, maintenance, electricity, various materials and the rest of the workforce that was not included as a cost of boning products were prorated to the volume produced. The method used was costing absorption. The purchase cost of the cuts of meat sheep showed little variation during three months as well as the types of court. Although the cost of buying beef was varied during the months, the types of court also varied. Products like agulha, palette, chest and tip of beef osso buco and pork sausage had negative gross margin. The entity should study the best way to price its sales and improve spending controls in order to determine more accurately the costs of its products.

Keywords: Cost Sets. Butcher. Consumer cooperative.

\section{INTRODUÇÃO}

O século XVIII, período da Revolução Industrial, caracterizou-se como uma época de mudanças tecnológicas gerando impacto no processo produtivo em nível econômico e social. Em conseqüência, o surgimento das indústrias fez surgir a contabilidade de custos devido a necessidade de se avaliar os estoques nas indústrias, servindo de base estrutural para as empresas comerciais. Hoje, a contabilidade é uma das maiores produtoras de informações de apoio para os gestores. Informações estas obtidas através de relatórios e demonstrativos que contêm dados relevantes que passaram a contribuir no processo de tomada de decisões. Devido à competitividade existente entre as organizações atuais, a contabilidade de custos tornou-se uma ferramenta necessária, pois gera informações para que a empresa tenha condições de melhor alocar os recursos em suas áreas de maior rentabilidade (CREPALDI, 2004). 
Gestão de custos no setor açougue de uma cooperativa de consumo. Andréa Oliveira da Silveira, Ana Paula Meneghetti Borges, Maria Dolores Pohlmann Velasquez

Além da concorrência existente no mercado há também a busca por diferenciação dos produtos. Essas exigências no ambiente dos negócios tornam constante a busca pela melhor tomada de decisões e a correta gestão dos custos pode proporcionar à empresa sua manutenção no mercado. Por isso, o uso de um método de custeio adequado pode contribuir com informações que auxiliem no processo decisório. A formação de custos num açougue, por exemplo, é diferenciada dos demais setores de um supermercado. Para se calcular corretamente a rentabilidade da área há de se considerar que no açougue há entradas diretas de cortes ou de peças. Cada tipo de entrada deve ter sua forma de cálculo e deve ter um sistema para administrar esses custos. Muitos varejistas analisam o custo dos cortes com o custo da peça (traseiro/dianteiro) menos a perda, porém não analisam de fato a sua participação dentro do desmembramento da peça. Dessa forma, quando comprados os cortes, existem os subprodutos que são os pedaços e bifes, cada um deve ser calculado separadamente, encontrando assim o custo real, já que um corte nunca será vendido em sua totalidade e sempre haverá alguma perda (MINGATOS, 2011).

Deste modo, o conhecimento dos custos é importante não somente para saber se determinado produto é rentável ou não, como também para indicar se é possível diminuir seus custos. Para que se obtenha um resultado satisfatório, é necessário um planejamento que inicie desde a busca do menor preço na compra da matéria prima, uso de mão de obra qualificada até a escolha dos fornecedores que disponham de produtos de boa qualidade e que ofereçam boas condições de pagamento. Sendo assim, é relevante salientar a importância do cálculo dos custos para qualquer empresa, seja uma indústria, uma prestadora de serviço ou até mesmo uma cooperativa, pois este cálculo possibilita determinar qual o custo exato do produto vendido ou do serviço prestado, e através disso obter uma margem de lucro ou sobra desejável. No caso das cooperativas de consumo, apesar de não visarem lucro, já que se caracterizam pelo fornecimento de bens aos associados, um planejamento de custos torna-se necessário na medida em que um método de custeio adequado proporciona para a entidade melhor controle e segurança aos cooperados. 
Gestão de custos no setor açougue de uma cooperativa de consumo. Andréa Oliveira da Silveira, Ana Paula Meneghetti Borges, Maria Dolores Pohlmann Velasquez

Nessa ótica, a partir da identificação das etapas do processo produtivo, a o estudo objetiva determinar mediante a utilização de um método de custeio específico o custo dos produtos no setor de açougue em uma cooperativa de consumo.

\section{REFERENCIAL TEÓRICO}

Devido à evolução da atividade econômica e a necessidade do controle dos estoques nas indústrias, a apuração de custos se fez importante no início do século XVIII, pois era por meio da contabilidade que se poderia obter a resposta se o negócio era rentável. A contabilidade de custos originou-se da contabilidade financeira ou geral, com o objetivo de separar os custos dos produtos vendidos, dos custos dos produtos que permaneciam no estoque (CREPALDI, 2004). A contabilidade de custos deve suprir, através de informações contábeis gerenciais, todas as áreas da entidade e, tendo em vista que cada segmento da empresa utiliza a informação contábil de maneira diversa, cabe à contabilidade de custos prover as informações específicas a cada área.

A contabilidade de custos se utiliza de termos particulares para denominar seus conceitos, sendo que cada terminologia possui significados distintos: custo, desembolso, despesa, gasto, investimento e perda.

Custo é o valor de mutação patrimonial qualitativa, ocorrida no ciclo operacional interno de uma entidade. Conforme Oliveira e Perez Jr.(2000), custos são gastos que a entidade realiza com o objetivo de colocar 0 seu produto pronto para ser comercializado, fabricando-o ou apenas revendendo-o. Custos compreendem todos os gastos relativos aos bens e serviços consumidos na produção de outros bens, bem como, os consumidos na prestação de serviços.

O desembolso, de acordo com Martins (2003), representa o pagamento resultante da aquisição do bem ou serviço. Pode ocorrer antes, durante ou após a entrada da utilidade comprada, portanto defasada ou não do momento do gasto. No âmbito contábil, a despesa é o gasto necessário para a obtenção de receita. Conforme Bernardi (1998), são gastos inerentes à obtenção de receitas e administração da 
Gestão de custos no setor açougue de uma cooperativa de consumo. Andréa Oliveira da Silveira, Ana Paula Meneghetti Borges, Maria Dolores Pohlmann Velasquez

empresa, portanto próprios das atividades de vendas e administração. Os gastos são os sacrifícios financeiros com os quais uma organização tem que arcar a fim de obter um produto, bem ou serviço qualquer. A compra de um produto ou serviço qualquer, que gera sacrifício financeiro para entidade significa um desembolso representado pela entrega ou promessa de entrega de ativos, normalmente dinheiro (MARTINS, 2003).

Investimento equivale a aplicação de capital em meios de produção ou a compra de ativos financeiros. Para Santos (2005), são todos os bens e direitos registrados no ativo das empresas para baixa em função de venda, amortização, consumo, desaparecimento, perecimento ou desvalorização.Por outro lado, quando os gastos não são intencionais, decorrentes de fatores externos e consumidos de forma anormal ou involuntária que não geram um novo bem ou serviço e tampouco geram receitas sendo apropriados diretamente no resultado, são reconhecidos como perdas (OLIVEIRA; PEREZ JR., 2000).

Outra classificação característica da contabilidade de custos relaciona-se aos custos e despesas, os quais apresentam classificações específicas. Os custos diretos, por exemplo, constituem todos aqueles elementos de custo individualizáveis com respeito ao produto ou serviço, isto é, se identificam imediatamente com a produção dos mesmos, mantendo uma correspondência proporcional.

Conforme Bertó e Beulke (2006) são aqueles relativos à aquisição da mercadoria ou relativos ao emprego de material direto no processamento industrial dos bens. Já o custo indireto é o que não se pode apropriar diretamente a cada tipo de bem ou função de custo no momento de sua ocorrência, ou seja, aquele que apenas mediante aproximação pode ser atribuído aos produtos por algum critério de rateio.

Segundo Santos (2005), custos indiretos são os outros custos que complementam uma atividade e são incorridos de forma indireta ou geral, beneficiando, dessa maneira, todos os bens ou serviços produzidos ou serviços prestados. Por outro lado, o custo fixo não sofre alteração de valor em caso de aumento ou diminuição da produção. Independe, portanto, do nível de atividade e do volume de produção ou venda. Representam a capacidade instalada que uma empresa possui para produzir e 
Gestão de custos no setor açougue de uma cooperativa de consumo. Andréa Oliveira da Silveira, Ana Paula Meneghetti Borges, Maria Dolores Pohlmann Velasquez

vender bens, serviços e mercadorias (SANTOS, 2005). Quando o custo se modifica em relação direta com o volume de bens vendidos ou serviços prestados é considerado custo variável ou marginal o qual, segundo Santos (2005), é diretamente relacionado com o volume de produção ou venda.

Com referência às despesas, têm-se as consideradas fixas, cujo total não varia proporcionalmente ao volume produzido ou ao volume de vendas, ou seja, existem despesas a serem pagas independentemente da quantidade produzida ou do valor de vendas. Bertó e Beulke (2006) relatam que sua característica é a de se manterem inalteradas face ao volume de atividade, dentro de certos limites de capacidade e não se modificam em razão do crescimento ou da retração do volume dos negócios dentro desses limites. De outra forma, a despesa variável é aquela que varia proporcionalmente ao volume produzido ou ao volume vendido, ou seja, só haverá despesa se houver venda ou unidades produzidas. De acordo com Bertó e Beulke (2006), as despesas variáveis constituem valores que se modificam em relação direta com o volume vendido.

A apropriação dos custos aos bens e serviços ocorre através dos métodos de custeio. De acordo com Koliver (2009), um sistema de custeio consiste num conjunto ordenado de idéias e meios de ação que objetiva a distribuição dos custos entre os bens e serviços produzidos e as funções geradoras de despesas do período. Dentre os métodos de custeio existentes, tem-se o custeio por absorção, o custeio variável e o método de custeio baseado nas atividades (Activity Based Costing -ABC).

O primeiro consiste na apuração de todos os custos na operação dos bens produzidos ou serviços prestados, sejam eles fixos ou variáveis e resulta na apropriação de todos os custos das funções de fabricação, administração e vendas dos bens e serviços produzidos, tanto diretos como indiretos. Fonseca e Linhares (2003) defendem a idéia de que os produtos devem absorver todos os custos necessários para a fabricação, não importando se são fixos ou variáveis. O método de custeio variável fundamenta-se na separação dos gastos em fixos e variáveis. Conforme Cruz (2006), os custos variáveis são considerados na avaliação de estoques enquanto os custos 
fixos são lançados no resultado. O sistema $A B C$ procura amenizar as distorções provocadas pelo uso do rateio, principalmente no que tange ao sistema de custeio por absorção. Martins (2003) informa que o custeio baseado em atividades procura reduzir sensivelmente as distorções provocadas pelo rateio arbitrário dos custos indiretos.

É comum em muitas atividades empresariais a existência de organizações que utilizam o mesmo ambiente para a produção de diversos co-produtos ou subprodutos, muitas vezes com a utilização das mesmas matérias primas, máquinas e mão-de-obra. Surge então a produção conjunta, que é a fabricação de diversos produtos a partir de uma mesma matéria-prima, comum a todos os produtos acabados. Conforme Martins (2003), produção conjunta é o aparecimento de diversos produtos a partir, normalmente, da mesma matéria prima. Vieira (2008) cita como exemplo o frigorífico, onde a partir de uma única matéria prima, que é o gado, são extraídos diferentes produtos como o couro e os diversos cortes de carne. Tem-se então os co-produtos, assim consideradas as carnes nobres e de segunda, enquanto que os órgãos, o couro e outras partes podem ser considerados subprodutos. Os órgãos, quando processados, podem se transformar em co-produtos.

A produção conjunta requer apropriação de custos conjuntos, sendo necessária a escolha de um método adequado para que a alocação dos custos ocorra da forma mais correta possível. Dessa forma, quando se utiliza o método do valor de mercado os custos conjuntos são distribuídos aos produtos de acordo com as unidades produzidas, ponderadas pelo preço de vendas dos produtos no ponto de separação.

Este método sugere uma relação entre o preço de venda e o custo incorrido no processo produtivo, considerando que diferentes preços decorrem da maior ou menor dificuldade em sua elaboração, evidenciando-se desta forma que os produtos que tiverem maior preço de mercado receberão maior custo. Este método é o mais praticado, tendo em vista a alegação de que os produtos de maior valor são os que recebem ou tem condições de receber maior parcela de custos. Talvez seu grande mérito esteja no fato de distribuir o resultado de forma homogênea aos co-produtos (MARTINS, 2003). 
No método das quantidades físicas os custos conjuntos são atribuídos aos produtos com base em alguma medida física, que pode ser expressa em unidades como quilos, toneladas e litros. De acordo com Hansen e Mowen (2001), o método de unidades físicas tenta alocar os custos conjuntos de acordo com os benefícios recebidos de cada um dos produtos finais. Assim supõe-se que cada unidade de matéria prima no produto final custa tanto para produzir quanto qualquer outra.

O método da igualdade do lucro bruto distribui o custo conjunto de forma que cada produto final tenha o mesmo lucro bruto por unidade. Martins (2003) relata que por este método os custos conjuntos são distribuídos de modo que cada produto tenha 0 mesmo lucro por unidade.

Por fim, o método das ponderações indica que os produtos conjuntos deveriam receber os custos conjuntos respeitando as dificuldades encontradas para sua obtenção e devido a isso são atribuídos fatores de ponderação como: peso por unidade, tamanho do produto, dificuldade na elaboração, tempo consumido na fabricação, tipo de mão de obra utilizada, quantidade de material, dentre outros. Nesse método, o número de unidades de cada produto é multiplicado pelo fator de ponderação correspondente e em seguida é multiplicado pelo custo médio unitário para se determinar a apropriação dos custos. Hansen e Mowen (2001) mencionam que o uso de fatores de ponderação cuidadosamente construídos habilita o contador de custos a dar mais atenção para várias influências e, portanto, resulta em alocações mais justas.

\section{METODOLOGIA}

O estudo foi desenvolvido em um açougue de uma cooperativa de consumo no município de Santa Maria/RS, Brasil, cujo período refere-se ao último trimestre de 2010. Este tipo de pesquisa caracteriza-se por ser um estudo concentrado de um ou de poucos objetos, de modo que permite conhecimentos amplos e detalhados do mesmo (BEUREN, 2008). O estudo tem caráter descritivo e quanto à abordagem do problema refere-se a uma pesquisa quantitativa. 
A coleta dos dados foi efetuada por meio de entrevistas com os responsáveis pelo açougue, bem como através da análise dos documentos disponibilizados pela entidade. Por ocasião da coleta de dados foram identificadas as etapas do processo produtivo do setor sob análise, possibilitando o levantamento e classificação dos custos naquele setor. Após a coleta de dados procedeu-se a alocação dos custos aos produtos utilizando-se como método o custeio por absorção. O custo dos produtos adquiridos prontos (carne aviária, bovina e suína) foi determinado através do custo médio, já para o cálculo dos custos dos co-produtos (produtos que se originam de uma mesma matéria prima - carne bovina e ovina) foi utilizado o rateio dos custos conjuntos através do método do valor de mercado que distribui os custos pelo potencial de venda de cada produto. Parte do custo da mão de obra foi rateado ao serviço de desossa no somatório dos custos conjuntos e o restante distribuído a todos os produtos de acordo com a quantidade produzida no período.

No cálculo do custo da carne bovina foi necessário separar as compras advindas de carcaças e de boi casado (tipos de cortes), pois apresentam rendimentos diferentes. Como a cooperativa também compra carne bovina pronta para ser vendida, após o cálculo do custo de cada corte de carne foi calculado o custo total médio mensal de todos os cortes da carne bovina, uma vez que não há como separar no ato da venda a origem do corte, se oriunda da matéria prima ou do produto comprado pronto.

Em acréscimo, foram apurados outros custos de produção como a depreciação de máquinas e do imóvel, manutenção de máquinas e equipamentos, energia elétrica, material de higiene e limpeza, material para embalagem dos produtos e o restante da mão de obra que não foi incluído como custo de desossa, conforme relatórios contábeis fornecidos pelo setor.

Por fim, foi comparado o custo unitário de cada produto com o preço de venda praticado, chegando-se à margem bruta por quilo após diminuídos os impostos. 


\section{RESULTADOS E DISCUSSÃO}

Conforme já exposto no capítulo da metodologia, o enfoque da pesquisa deu-se no setor açougue de uma cooperativa de consumo, onde se buscou determinar o custo dos produtos daquele setor. A organização do processo produtivo do açougue encontra-se estruturada em etapas, a saber: compra da matéria-prima (carne bovina, suína, ovinos e aves), preparo da matéria-prima, estocagem e armazenamento dos produtos, exposição dos produtos e atendimento ao cliente.

O processo de suprimento das mercadorias e geração de estoques ocorre sob duas formas: por meio da compra de produtos acabados (aqueles que são prontos para a venda) e de matéria prima (que passam pelo processo de desossa).

As carnes suínas (costela, filé suíno, lombo, linguiça, pernil, ponta da costela, costela defumada, pé suíno, pele suína, pernil e rabo) e as carnes aviárias (coxa e sobre coxa, coxinha da asa, filé de peito, lingüiça, moela, sobre coxa, frango colonial, peito de frango, chester, coração de frango, frango inteiro e peru temperado) são adquiridas prontas para serem vendidas.

A apuração do custo da compra de produtos acabados ocorre sem necessidade de processamento no açougue. Com base nas notas fiscais de entrada, o custo médio foi determinado através da divisão do valor total de aquisição de cada produto pela quantidade adquirida, conforme mostra a Tabela 1. No caso das aves foi considerado o valor de aquisição já descontado os impostos, enquanto a carne suína é isenta de tributação. 
Gestão de custos no setor açougue de uma cooperativa de consumo. Andréa Oliveira da Silveira, Ana Paula Meneghetti Borges, Maria Dolores Pohlmann Velasquez

Tabela 1 - Custo médio mensal da carne aviária e suína, último trimestre de 2010.

\begin{tabular}{|c|c|c|c|c|}
\hline Item & Descrição & $\begin{array}{c}\text { Quantidade } \\
\text { adquirida }(\mathrm{Kg})\end{array}$ & $\begin{array}{c}\text { Valor de } \\
\text { aquisição (R\$) }\end{array}$ & Custo médio/Kg (R\$) \\
\hline Outubro & & & & \\
\hline \multirow{6}{*}{$\begin{array}{c}\text { Carne } \\
\text { Aviária }\end{array}$} & $\begin{array}{l}\text { Coxa/sobre coxa } \\
\text { Coxinha da asa }\end{array}$ & 990,00 & $3.357,00$ & 3,39 \\
\hline & Filé de peito & 278,00 & $1.198,50$ & 4,31 \\
\hline & Lingüiça & 36,00 & 200,52 & 5,57 \\
\hline & Moela & $\begin{array}{l}15,00 \\
15,00\end{array}$ & $\begin{array}{l}65,40 \\
48,00\end{array}$ & $\begin{array}{l}4,36 \\
3,20\end{array}$ \\
\hline & Sobre coxa & $\begin{array}{l}15,00 \\
150,00\end{array}$ & $\begin{array}{l}48,00 \\
568,50\end{array}$ & $\begin{array}{l}3,20 \\
3,79\end{array}$ \\
\hline & Total & $1.484,00$ & $5.437,92$ & 3,66 \\
\hline \multirow{7}{*}{$\begin{array}{l}\text { Carne } \\
\text { Suína }\end{array}$} & Costela & 107,90 & 939,35 & 8,71 \\
\hline & Filé suíno & 20,00 & 144,00 & 7,20 \\
\hline & Lombo & 16,70 & 177,02 & 10,60 \\
\hline & Lingüiça & 279,38 & $1.949,00$ & 6,98 \\
\hline & Pernil & 106,02 & 567,75 & 5,36 \\
\hline & Ponta da costela & 4,80 & 55,68 & 11,60 \\
\hline & Total & 534,80 & $3.832,80$ & 7,17 \\
\hline Novembro & & & & \\
\hline \multirow{6}{*}{$\begin{array}{l}\text { Carne } \\
\text { Aviária }\end{array}$} & Coxa/sobre coxa & 255,00 & 880,50 & 3,45 \\
\hline & Coxinha da asa & 170,00 & 816,00 & 4,80 \\
\hline & Filé de peito & 245,00 & $1.319,52$ & 5,39 \\
\hline & Frango colonial & 12,80 & 47,36 & 3,70 \\
\hline & Peito de frango & 466,00 & $1.618,98$ & 3,47 \\
\hline & Total & $1.148,80$ & $4.682,36$ & 4,08 \\
\hline \multirow{4}{*}{$\begin{array}{l}\text { Carne } \\
\text { Suína }\end{array}$} & Costela & 77,70 & 699,30 & 9,00 \\
\hline & Lingüiça & 119,90 & 967,00 & 8,07 \\
\hline & Ponta da costela & 5,20 & 60,32 & 11,60 \\
\hline & Total & 202.80 & $1.726,62$ & 8,51 \\
\hline Dezembro & & & & \\
\hline \multirow{12}{*}{$\begin{array}{l}\text { Carne } \\
\text { Aviária }\end{array}$} & Chester & 250,00 & $2.100,00$ & 8,40 \\
\hline & Coração frango & 180,00 & $1.890,00$ & 10,50 \\
\hline & Coxa/sobre coxa & $1.120,00$ & $3.995,00$ & 3,57 \\
\hline & Coxinha da asa & 270,00 & $1.377,00$ & 5,10 \\
\hline & Filé de peito & 354,00 & $1.969,24$ & 5,56 \\
\hline & Frango colonial & 21,20 & 80,56 & 3,79 \\
\hline & Frango inteiro & 135,20 & 761,93 & 5,64 \\
\hline & Lingüiça & 45,00 & 228,15 & 5,07 \\
\hline & Peito de frango & 170,00 & 629,00 & 3,70 \\
\hline & Peru temperado & 67,10 & 599,71 & 8,94 \\
\hline & Sobre coxa & 222,00 & 950,16 & 4,28 \\
\hline & Total & $2.834,50$ & $14.580,75$ & 5,14 \\
\hline \multirow{9}{*}{$\begin{array}{l}\text { Carne } \\
\text { Suína }\end{array}$} & Costela & 119,50 & $1.229,19$ & 10,28 \\
\hline & Costela defumada & 5,00 & 72,50 & 14,50 \\
\hline & Lombo & 134,00 & $1.605,31$ & 11,98 \\
\hline & Lingüiça & 245,20 & $2.084,20$ & 8,50 \\
\hline & Pé suíno & 5,00 & 17,50 & 3,50 \\
\hline & Pele suína & 5,00 & 12,50 & 2,50 \\
\hline & Pernil & 269,50 & $1.841,09$ & 6,83 \\
\hline & Rabo & 3,00 & 17,70 & 5,90 \\
\hline & Total & 786,20 & $6.879,99$ & 8,75 \\
\hline
\end{tabular}


Os dados indicam que as aquisições quanto aos tipos de produtos variam conforme o período. À exceção do coração de frango, chester e peru temperado, adquiridos no mês de dezembro, percebe-se que nos demais meses os produtos aviários apresentam variação em seus custos médios entre $R \$ 3,00$ e $R \$ 6,00$. Por outro lado, os custos médios das carnes suínas apresentam-se variados, provavelmente pela diversificação dos tipos de produtos.

A outra forma de aquisição refere-se a matéria prima que representa tudo aquilo que passa por um processo de transformação até tornar-se o produto acabado, como é o caso da carne bovina e ovina que são adquiridas em carcaças ou boi casado (produtos) e sofrem um processo de desossa sendo separadas em cortes de carne (coprodutos).

Do traseiro bovino, por exemplo, originam-se o coxão de dentro ou coxão mole, alcatra, maminha, filé mignon, patinho, coxão de fora ou duro, picanha, ripa da chuleta, chuleta, tatu lagarto, guisado, osso buço e cebo. Do dianteiro bovino obtêm-se cortes de carne como a paleta, agulha, ponta de peito, guisado, retalhos e cebo. Da costela bovina tem-se a costela janela, costela minga e cebo. Já da alcatra bola extrai-se o coxão de dentro ou mole, patinho, coxão de fora ou duro, tatu lagarto, guisado, osso buço e cebo. Além destes, há o boi casado que é composto de $48 \%$ de traseiro bovino, $38 \%$ de dianteiro bovino e $14 \%$ de costela bovina. Da carcaça de carne ovina são originados os cortes de costela ovina, paleta e pernil.

A desossa da matéria prima ocorre conforme a demanda, ou seja, somente nas quantidades utilizadas para a comercialização, sendo o restante estocado até 0 momento da venda. Eventualmente, há aquisição de cortes prontos de carne bovina para a venda.

Nesse ponto detectou-se a necessidade de apuração do custo por hora da mão de obra, considerando que a desossa requer o envolvimento do serviço do açougueiro cujos dados podem ser visualizados na Tabela 2. A apuração dos custos de pessoal compreende os gastos relacionados à admissão, aprendizagem, treinamento, desenvolvimento e formação, remuneração, encargos sociais e até mesmo gastos com 
Gestão de custos no setor açougue de uma cooperativa de consumo. Andréa Oliveira da Silveira, Ana Paula Meneghetti Borges, Maria Dolores Pohlmann Velasquez

desligamento do profissional. A partir daí, com base nas informações disponíveis na folha de pagamento da entidade, foi possível determinar o custo total com mão de obra do açougue que dispõe de um açougueiro com carga horária de 220 horas mensais. O custo por hora foi determinado dividindo-se o valor total mensal da folha de pagamento pelo número de horas efetivamente trabalhadas, descontado o tempo não trabalhado (domingos e feriados).

Tabela 2 - Custo mensal da mão de obra do açougueiro, último trimestre de 2010.

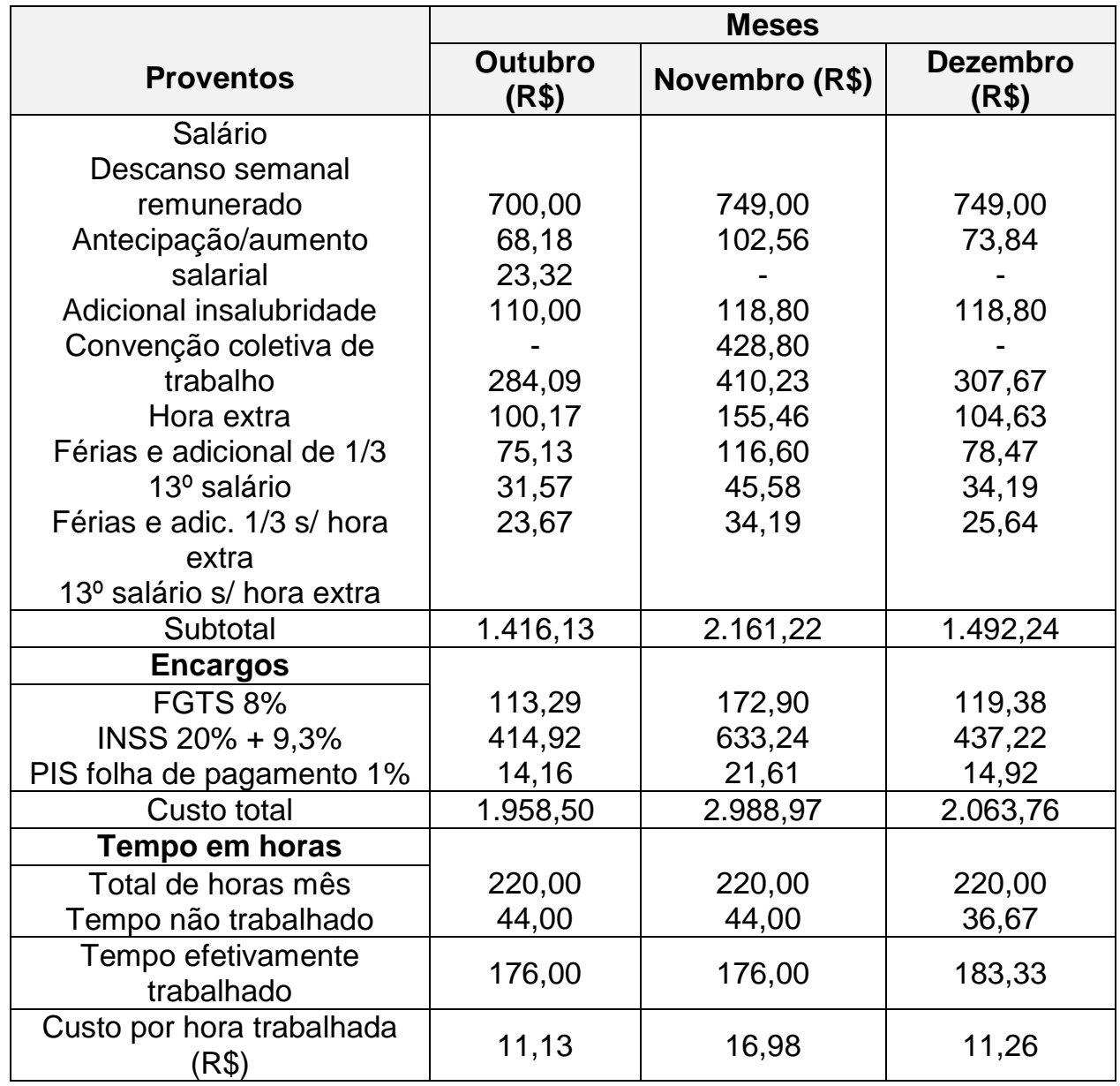

Fonte: dados da pesquisa

Observa-se que no mês de novembro houve um acréscimo do custo total mensal, o que resultou em um custo maior por hora trabalhada. $O$ motivo desse 
aumento deve-se ao pagamento da diferença da convenção coletiva de trabalho, ou seja, acordos que ocorrem entre sindicatos de trabalhadores e empregadores em que reajustes, pisos salariais, benefícios, direitos e deveres de empregadores e trabalhadores são objeto de negociações.

Calculado o custo por hora do açougueiro, foi possível apurar o custo de mão de obra utilizada na desossa das carnes ovinas e bovinas. Para determinar o custo total mensal da desossa utilizou-se a quantidade total de carcaças de carne bovina e ovina adquiridas por mês, multiplicada pelo tempo necessário para desossá-las, estimado em 10 minutos por carcaça. Esse resultado, obtido em minutos, foi convertido em horas e multiplicado pelo valor do custo por hora trabalhada do açougueiro conforme apurado na Tabela 2. A tabela 3 mostra o custo total de mão de obra mensal na desossa da carne bovina e ovina. 
Gestão de custos no setor açougue de uma cooperativa de consumo. Andréa Oliveira da Silveira, Ana Paula Meneghetti Borges, Maria Dolores Pohlmann Velasquez

Tabela 3 - Custo mensal da mão de obra do açougueiro na desossa da carne bovina e ovina, último trimestre de 2010.

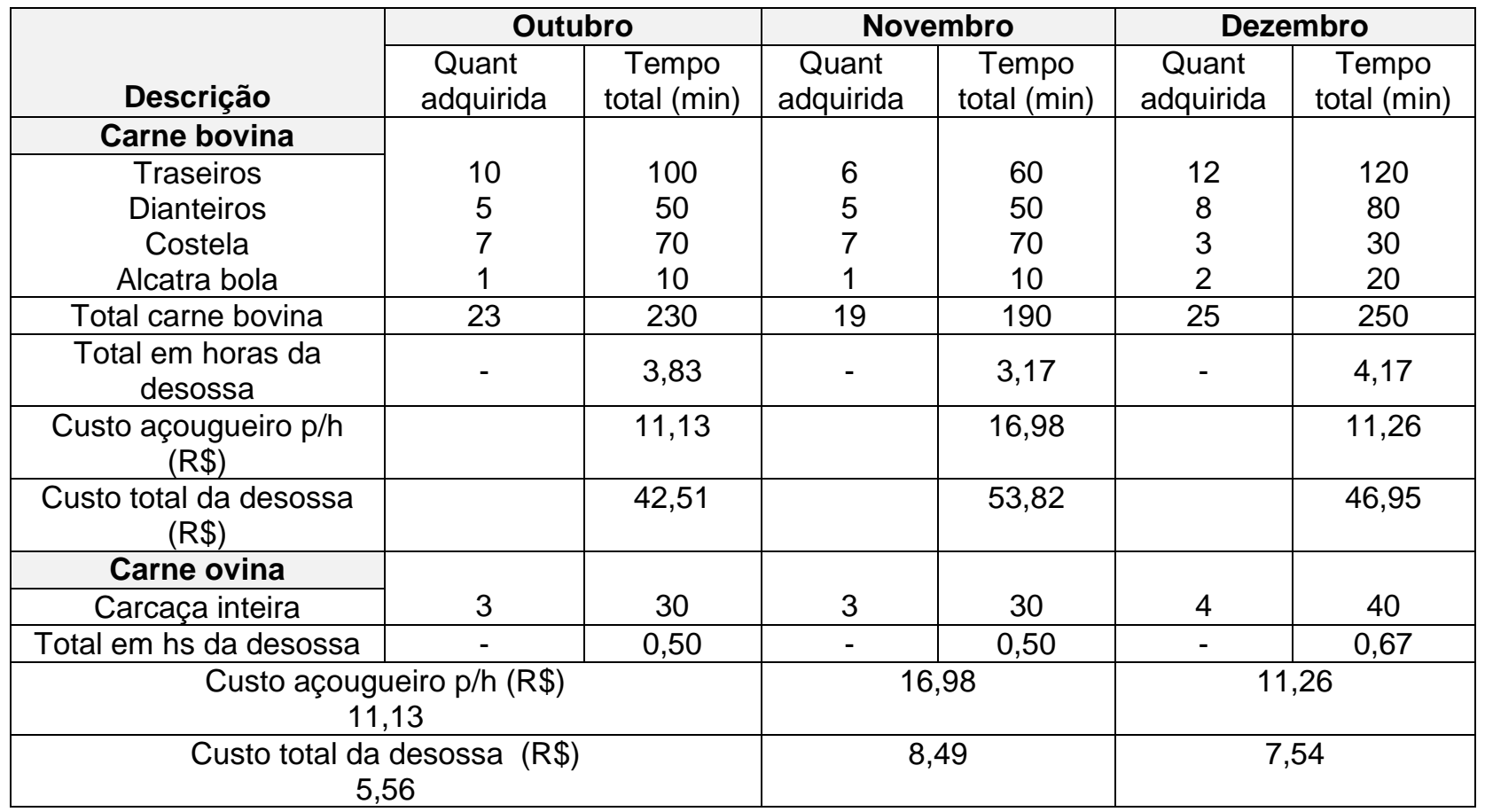

Fonte: dados da pesquisa

Embora a maior aquisição de carcaça, tanto bovina quanto ovina, tenha ocorrido em dezembro, o maior custo aconteceu no mês de novembro devido ao aumento do custo por hora da mão de obra do açougueiro ocasionado pelo pagamento da diferença da convenção coletiva de trabalho.

Em continuidade a apuração do custo da matéria prima, os dados da Tabela 3 devem ser adicionados ao valor de aquisição das carcaças bovinas e ovinas constantes nas notas fiscais de entrada. A conjugação desses dados (mão de obra e valor de compra) forma o custo conjunto desses produtos. Para determinar a quantidade em quilos de cada corte de carne, tanto bovina quanto ovina, multiplicou-se o total da quantidade da carcaça pela percentagem de rendimento fornecida pela cooperativa.

O rateio dos custos conjuntos aos quilos de cada corte de carne foi efetuado pelo método do valor de mercado, em que a base de rateio dos custos conjuntos é a receita total considerando que toda a produção seja vendida. Logo, para determinar a receita 
Gestão de custos no setor açougue de uma cooperativa de consumo. Andréa Oliveira da Silveira, Ana Paula Meneghetti Borges, Maria Dolores Pohlmann Velasquez

total multiplicou-se a quantidade em quilos pelo preço venda. A receita encontrada gera o percentual de rateio do custo para cada corte de carne, que multiplicado pelo valor total de compra da carcaça resulta no custo total de cada corte de carne. O cebo e os retalhos são considerados como perdas no processo de desossa e, portanto, não recebem custo.

A Tabela 4 contém os custos dos cortes de carne ovina apurados no período. Observa-se que os dados relativos ao número de carcaças adquiridas, o tempo de desossa e o custo da mão de obra foram extraídos da Tabela 3. Os demais dados foram fornecidos pela entidade.

Tabela 4 - Custo mensal de compra dos cortes de carne ovina, último trimestre de 2010

\begin{tabular}{|c|c|c|c|c|c|c|c|}
\hline \multirow{2}{*}{ Descrição } & \multicolumn{2}{|c|}{ Rendimento } & \multicolumn{3}{|c|}{ Preço de venda } & \multicolumn{2}{|c|}{$\begin{array}{l}\text { Custo conjunto } \\
\text { (R\$) }\end{array}$} \\
\hline & $\%$ & $\mathrm{Kg}$ & kg (R\$) & Total $(\mathbf{R} \$)$ & $\%$ & Total & Unitário \\
\hline Outubro & \multirow{4}{*}{$\begin{array}{l}36,90 \\
44,18 \\
18,92\end{array}$} & \multirow{4}{*}{$\begin{array}{l}23,40 \\
28,00 \\
12,00 \\
\end{array}$} & \multirow{4}{*}{$\begin{array}{l}14,27 \\
14,27 \\
14,27 \\
\end{array}$} & \multirow{4}{*}{$\begin{array}{l}333,91 \\
399,56 \\
171,24\end{array}$} & \multirow{4}{*}{$\begin{array}{l}36,90 \\
44,18 \\
18,92 \\
\end{array}$} & \multirow{4}{*}{$\begin{array}{l}259,00 \\
310,07 \\
132,79\end{array}$} & \multirow{4}{*}{$\begin{array}{l}11,07 \\
11,07 \\
11,07\end{array}$} \\
\hline Pernil & & & & & & & \\
\hline Costela & & & & & & & \\
\hline Paleta & & & & & & & \\
\hline Total & 100,00 & 63,40 & 14,27 & 904,71 & 100,00 & 701,86 & 11,07 \\
\hline \multicolumn{8}{|l|}{ Novembro } \\
\hline Pernil & 36,90 & 27,50 & 14,27 & 391,68 & 37,19 & 290,26 & 10,57 \\
\hline Costela & 44,18 & 32,90 & 14,02 & 460,67 & 43,74 & 341,40 & 10,39 \\
\hline Paleta & 18,92 & 14,10 & 14,27 & 200,83 & 19,07 & 148,83 & 10,57 \\
\hline Total & 100,00 & 74,40 & 42,55 & $1.053,18$ & 100,00 & 780,49 & 10,49 \\
\hline \multicolumn{8}{|l|}{ Dezembro } \\
\hline Pernil & 36,90 & 64,30 & 14,21 & 913,65 & 36,84 & 667,91 & 10,39 \\
\hline Costela & 44,18 & 77,00 & 14,27 & $1.098,06$ & 44,27 & 802,72 & 10,43 \\
\hline Paleta & 18,92 & 33,00 & 14,21 & 468,46 & 18,89 & 342,46 & 10,39 \\
\hline Total & 100,00 & 174,20 & 42,70 & $2.480,18$ & 100,00 & $1.813,10$ & 10,41 \\
\hline
\end{tabular}

Fonte: Dados da pesquisa

Verifica-se que no mês de outubro o preço médio de venda por quilo é o mesmo para os três tipos de corte o que gera um mesmo custo unitário para todos os cortes. Nos meses de novembro e dezembro, como houve variação do preço médio de venda da costela com relação aos outros produtos, ocorreu também variação no custo unitário.

Também para a carne bovina foi feito o rateio dos custos conjuntos (matéria prima e mão de obra) com base no faturamento total de cada produto, considerando 
Gestão de custos no setor açougue de uma cooperativa de consumo. Andréa Oliveira da Silveira, Ana Paula Meneghetti Borges, Maria Dolores Pohlmann Velasquez

toda a produção vendida. A aquisição da matéria prima da carne bovina dá-se através de carcaças e boi casado, os quais apresentam diferentes percentuais de rendimento e vários subprodutos. Devido a existência de carne bovina adquirida pronta para revenda e pela impossibilidade de segregar no momento da venda se oriunda da desossa ou não, calculou-se o custo médio de toda carne bovina movimentada no açougue em cada mês que por limitação de espaço os dados foram resumidos conforme mostra a Tabela 5.

Tabela 5 - Custo de compra mensal por corte de carne bovina, último trimestre de 2010.

\begin{tabular}{|c|c|c|c|}
\hline Cortes de carne & $\begin{array}{c}\text { Quantidade } \\
\mathbf{( K g )}\end{array}$ & Valor total (R\$) & $\begin{array}{c}\text { Custo médio/Kg } \\
\text { (R\$) }\end{array}$ \\
\hline Outubro & & & \\
Agulha & 273,40 & $1.488,98$ & 5,45 \\
Alcatra & 700,40 & $8.289,76$ & 11,84 \\
Chuleta & 374,90 & $2.493,51$ & 6,65 \\
Costela minga & 277,70 & $1.528,37$ & 5,50 \\
Costela janela & 450,30 & $3.414,71$ & 7,58 \\
Coxão de fora ou duro & 319,90 & $3.116,76$ & 9,74 \\
Coxão mole ou de & 499,70 & $5.504,74$ & 11,02 \\
dentro & 88,50 & $1.475,95$ & 16,68 \\
Filé mignon & 592,00 & $2.714,54$ & 4,59 \\
Guisado & 63,70 & 912,02 & 14,32 \\
Maminha & 10,00 & 35,00 & 3,50 \\
Miúdos & 173,20 & 501,11 & 2,89 \\
Osso buco & 187,30 & $1.414,44$ & 7,55 \\
Paleta & 311,90 & $3.317,55$ & 10,64 \\
Patinho & 94,20 & $1.484,67$ & 15,76 \\
Picanha & 129,60 & 641,15 & 4,95 \\
Ponta de peito & 232,60 & $1.912,02$ & 8,22 \\
Ripa da chuleta & 111,30 & $1.216,92$ & 10,93 \\
Tatu lagarto & $4.890,50$ & $41.462,20$ & 8,48 \\
\hline Total & & & \\
\hline Novembro & & & \\
\hline
\end{tabular}


Gestão de custos no setor açougue de uma cooperativa de consumo. Andréa Oliveira da Silveira, Ana Paula Meneghetti Borges, Maria Dolores Pohlmann Velasquez

\begin{tabular}{|c|c|c|c|}
\hline Agulha & 155,20 & 853,26 & 5,50 \\
\hline Alcatra & $1.121,60$ & $11.422,75$ & 10,18 \\
\hline Chuleta & 271,30 & $2.072,29$ & 7,64 \\
\hline Costela minga & 300,80 & $1.923,23$ & 6,39 \\
\hline Costela janela & 487,90 & $4.114,10$ & 8,43 \\
\hline Coxão de fora ou duro & 274,50 & $2.848,39$ & 10,38 \\
\hline Coxão mole ou de & 716,70 & $8.072,17$ & 11,26 \\
\hline dentro & 114,10 & $2.028,21$ & 17,77 \\
\hline Filé mignon & 472,40 & $2.407,43$ & 5,10 \\
\hline Guisado & 79,20 & $1.175,14$ & 14,84 \\
\hline Maminha & 30,50 & 87,75 & 2,88 \\
\hline Miudos & 124,10 & 357,67 & 2,88 \\
\hline Osso buco & 230,40 & $1.807,19$ & 7,84 \\
\hline Paleta & 561,30 & $6.096,66$ & 10,86 \\
\hline Patinho & 105,20 & $1.758,21$ & 16,71 \\
\hline Picanha & 159,50 & 862,80 & 5,41 \\
\hline Ponta de peito & 173,40 & $1.519,21$ & 8,76 \\
\hline Ripa da chuleta & 81,60 & 932,56 & 11,42 \\
\hline $\begin{array}{l}\text { Tatu lagarto } \\
\text { Vazio }\end{array}$ & 11,90 & 118,50 & 10,00 \\
\hline Total & & & \\
\hline Dezembro & $5.4 / 1,10$ & $50.45 /, 52$ & 9,22 \\
\hline Agulha & 307,70 & $2.062,72$ & 6,70 \\
\hline Alcatra & 920,00 & $11.815,79$ & 12,84 \\
\hline Chuleta & 542,10 & $4.458,54$ & 8,23 \\
\hline Costela minga & 80,30 & 570,80 & 7,11 \\
\hline Costela janela & 148,70 & $1.327,56$ & 8,93 \\
\hline Coxão de fora ou duro & 675,60 & $6.989,59$ & 10,35 \\
\hline Coxão mole ou de & 818,70 & $10.403,28$ & 12,71 \\
\hline dentro & 138,10 & $3.495,85$ & 25,31 \\
\hline Filé mignon & 892,90 & $4.516,11$ & 5,06 \\
\hline Guisado & 182,10 & $2.955,68$ & 16,23 \\
\hline Maminha & 4,00 & 14,00 & 3,50 \\
\hline Miúdos & 255,60 & 792,92 & 3,10 \\
\hline Osso buco & 302,30 & $2.144,03$ & 7,09 \\
\hline Paleta & 716,30 & $7.564,91$ & 10,56 \\
\hline Patinho & 144,10 & $2.751,51$ & 19,10 \\
\hline Picanha & 209,20 & $1.059,49$ & 5,06 \\
\hline Ponta de peito & 333,30 & $3.429,88$ & 10,29 \\
\hline Ripa da chuleta & 163,20 & $1.951,38$ & 11,96 \\
\hline $\begin{array}{c}\text { Tatu lagarto } \\
\text { Vazio }\end{array}$ & 11,70 & 117,00 & 10,00 \\
\hline Total & $6.845,90$ & $68.421,04$ & 9,99 \\
\hline
\end{tabular}

Fonte: dados da pesquisa.

Observa-se que para todos os períodos analisados o filé mignon e a picanha foram os produtos de maior custo médio enquanto que osso buço e miúdos 
Gestão de custos no setor açougue de uma cooperativa de consumo. Andréa Oliveira da Silveira, Ana Paula Meneghetti Borges, Maria Dolores Pohlmann Velasquez

apresentaram menor custo. A alcatra foi o produto adquirido em maior quantidade, sendo o vazio e miúdos os produtos de menor aquisição.

$\mathrm{Na}$ sequência foram apurados outros custos: depreciação, energia elétrica, material de higiene e limpeza, material de embalagem e etiquetagem, mão de obra do chefe do açougue acrescida de parte da mão de obra do açougueiro que não foi alocada à desossa. Estes custos não estão relacionados diretamente a um produto específico e foram rateados a todos os produtos pelo volume produzido. O custo por quilo foi obtido através da soma dos outros custos divididos pela quantidade total de carne adquirida mensalmente informado na Tabela 6.

Tabela 6 - Outros custos mensais do açougue, último trimestre de 2010.

\begin{tabular}{|c|c|c|c|}
\hline Outros custos & Outubro & Novembro & Dezembro \\
\hline Depreciação & 94,57 & 51,88 & 51,88 \\
Energia elétrica & 672,16 & 698,78 & 708,95 \\
Parte da mão de obra & $2.868,35$ & $4.383,70$ & $3.003,68$ \\
Embalagem, etiq, mat higiene e & 645,58 & - & - \\
limpeza & $4.280,66$ & $5.134,36$ & $3.764,51$ \\
\hline Total de outros custos $(\mathrm{R} \$)$ & $6.972,60$ & $6.897,70$ & $7.806,30$ \\
\hline Volume produzido $(\mathrm{kg})$ & 0,61 & 0,74 & 0,48 \\
\hline Custo por quilo $(\mathrm{R} \$)$ & &
\end{tabular}

Fonte: dados da pesquisa.

No mês de dezembro o custo por quilo foi o menor dos três meses, devido a não ter ocorrido custos com material de embalagem/etiquetagem e material de higiene/limpeza e a quantidade de carne adquirida ter sido a maior do período.

O custo médio de cada produto constante nas Tabelas 1, 4 e 5, acrescido do valor do custo por quilo disposto na Tabela 6 forma o custo total por quilo de cada produto conforme indica a quarta coluna das Tabelas 7, 8 e 9. Esse valor proporcionou apurar a margem bruta por produto calculada através da diferença entre o preço de venda líquido de impostos e o custo total por produto.

O imposto incidente para se determinar a margem bruta é o Imposto sobre Circulação de Mercadorias e Serviços (ICMS). Esse imposto é utilizado apenas na carne aviária cuja base de cálculo é de 58,333 \% do valor da operação e multiplicados 
Gestão de custos no setor açougue de uma cooperativa de consumo. Andréa Oliveira da Silveira, Ana Paula Meneghetti Borges, Maria Dolores Pohlmann Velasquez

pela alíquota de $12 \%$ pois é considerado produto da cesta básica (Lei Orgânica do ICMS n. 8.820/89 art.10, § 10). Os demais não apresentam valor do imposto, pois os produtos provenientes da carne bovina e ovina são substitutos tributários e a carne suína é isenta.

A Tabela 7 revela os custos totais e a respectiva margem bruta de cada produto no mês de outubro de 2010.

Tabela 7 - Custo total e margem bruta por produto, outubro de 2010

\begin{tabular}{|c|c|c|c|c|c|c|c|}
\hline \multirow[b]{2}{*}{ Produtos } & \multicolumn{3}{|c|}{ Custos (R\$) } & \multirow{2}{*}{$\begin{array}{l}\text { Preço de } \\
\text { venda } \\
\text { (R\$) }\end{array}$} & \multirow{2}{*}{$\begin{array}{l}\text { Impostos } \\
\text { (R\$) }\end{array}$} & \multirow{2}{*}{$\begin{array}{l}\text { Resultado } \\
\text { bruto (R\$) }\end{array}$} & \multirow{2}{*}{$\begin{array}{l}\text { Margem } \\
\text { bruta \% }\end{array}$} \\
\hline & Compra & Outros & Totais & & & & \\
\hline Agulha bovina & 5,45 & 0,61 & 6,06 & 5,12 & - & $(0,94)$ & $-18,35$ \\
\hline Alcatra bovina & 11,84 & 0,61 & 12,45 & 14,96 & - & 2,51 & 16,78 \\
\hline Chuleta bovina & 6,65 & 0,61 & 7,26 & 7,89 & - & 0,63 & 7,98 \\
\hline Costela janela bovina & 7,58 & 0,61 & 8,19 & 9,95 & - & 1,76 & 17,68 \\
\hline Costela minga bovina & 5,50 & 0,61 & 6,11 & 7,21 & - & 1,10 & 15,25 \\
\hline Costela ovina & 11,07 & 0,61 & 11,68 & 14,27 & - & 2,59 & 18,14 \\
\hline Costela suína & 8,71 & 0,61 & 9,32 & 10,33 & - & 1,01 & 9,78 \\
\hline Coxa/sobre coxa de frango & 3,39 & 0,61 & 4,00 & 4,89 & 0,34 & 0,55 & 11,24 \\
\hline Coxão de fora ou duro & 9,74 & 0,61 & 10,35 & 11,68 & - & 1,33 & 11,38 \\
\hline Coxão de dentro ou mole & 11,02 & 0,61 & 11,63 & 14,46 & - & 2,83 & 19,58 \\
\hline Coxinha da asa frango & 4,31 & 0,61 & 4,92 & 6,04 & 0,42 & 0,70 & 11,60 \\
\hline Filé mignon bovino & 16,68 & 0,61 & 17,29 & 19,80 & - & 2,51 & 12,66 \\
\hline Filé de peito de frango & 5,57 & 0,61 & 6,18 & 7,35 & 0,51 & 0,66 & 8,97 \\
\hline Filé suíno & 7,20 & 0,61 & 7,81 & 10,27 & - & 2,46 & 23,99 \\
\hline Guisado bovino & 4,59 & 0,61 & 5,20 & 5,58 & - & 0,38 & 6,86 \\
\hline Lingüiça de frango & 4,36 & 0,61 & 4,97 & 7,60 & - & 2,63 & 34,61 \\
\hline Lingüiça suína & 6,98 & 0,61 & 7,59 & 6,25 & - & $(1,34)$ & $-21,48$ \\
\hline Lombo suíno & 10,60 & 0,61 & 11,21 & 14,27 & - & 3,06 & 21,43 \\
\hline Maminha bovina & 14,32 & 0,61 & 14,93 & 16,99 & - & 2,06 & 12,11 \\
\hline Miúdos bovinos & 3,50 & 0,61 & 4,11 & 5,87 & - & 1,76 & 29,93 \\
\hline Moela de frango & 3,20 & 0,61 & 3,81 & 3,58 & 0,25 & $(0,48)$ & $-13,51$ \\
\hline Osso buco bovino & 2,89 & 0,61 & 3,50 & 3,37 & - & $(0,13)$ & $-3,75$ \\
\hline Paleta bovina & 7,55 & 0,61 & 8,16 & 7,69 & - & $(0,47)$ & $-6,18$ \\
\hline Paleta ovina & 11,07 & 0,61 & 11,68 & 14,27 & - & 2,59 & 18,14 \\
\hline Patinho bovino & 10,64 & 0,61 & 11,25 & 13,08 & - & 1,83 & 14,02 \\
\hline Pernil ovino & 11,07 & 0,61 & 11,68 & 14,27 & - & 2,59 & 18,14 \\
\hline Pernil suíno & 5,36 & 0,61 & 5,97 & 8,00 & - & 2,03 & 25,38 \\
\hline Picanha bovina & 15,76 & 0,61 & 16,37 & 18,72 & - & 2,35 & 12,54 \\
\hline Ponta de peito bovino & 4,95 & 0,61 & 5,56 & 5,03 & - & $(0,53)$ & $-10,50$ \\
\hline Ponta da Costela suína & 11,60 & 0,61 & 12,21 & 14,27 & - & 2,06 & 14,41 \\
\hline Ripa da chuleta bovina & 8,22 & 0,61 & 8,83 & 9,80 & - & 0,97 & 9,91 \\
\hline Sobre coxa de Frango & 3,79 & 0,61 & 4,40 & 4,54 & 0,32 & $(0,18)$ & $-3,99$ \\
\hline Tatu lagarto bovino & 10,93 & 0,61 & 11,54 & 12,79 & - & 1,25 & 9,77 \\
\hline Total & 266,09 & 20,13 & 286,22 & 330,19 & 1,84 & 42,13 & 12,76 \\
\hline
\end{tabular}


Gestão de custos no setor açougue de uma cooperativa de consumo. Andréa Oliveira da Silveira, Ana Paula Meneghetti Borges, Maria Dolores Pohlmann Velasquez

Observa-se que alguns produtos obtiveram margem bruta negativa no mês de outubro, como foi o caso da agulha bovina, linguiça suína, moela, osso buco bovino, paleta bovina e ponta de peito bovino e sobre coxa de frango. A lingüiça de frango revelou-se o produto mais lucrativo já que apresentou a maior margem bruta.

Os mesmos dados para o mês de novembro de 2010 encontram-se dispostos na Tabela 8.

Tabela 8 - Custo total dos produtos do açougue e margem bruta no mês de novembro/2010

\begin{tabular}{|c|c|c|c|c|c|c|c|}
\hline \multirow[b]{2}{*}{ Produtos } & \multicolumn{3}{|c|}{ Custos (R\$) } & \multirow{2}{*}{$\begin{array}{c}\text { Preço de } \\
\text { venda } \\
\text { (R\$) }\end{array}$} & \multirow{2}{*}{$\begin{array}{c}\text { Impostos } \\
\text { (R\$) }\end{array}$} & \multirow{2}{*}{$\begin{array}{l}\text { Resultado } \\
\text { bruto (R\$) }\end{array}$} & \multirow{2}{*}{$\begin{array}{l}\text { Margem } \\
\text { bruta \% }\end{array}$} \\
\hline & Compra & Outros & Totais & & & & \\
\hline Agulha bovina & 5,50 & 0.74 & 6.24 & 4.86 & - & $(1,38)$ & $-28,39$ \\
\hline Alcatra bovina & 10,18 & 0,74 & 10,92 & 16,76 & - & 5,84 & 34,85 \\
\hline Chuleta bovina & 7,64 & 0,74 & 8,38 & 8,81 & - & 0,43 & 4,91 \\
\hline Costela janela bovina & 8,43 & 0,74 & 9,17 & 10,30 & - & 1,13 & 10.96 \\
\hline Costela minga bovina & $\begin{array}{l}0,40 \\
6,39\end{array}$ & 0,74 & 7,13 & 7,81 & - & 0,68 & 8,70 \\
\hline Costela ovina & 10,39 & 0,74 & 11,13 & 14,02 & - & 2,89 & 20,59 \\
\hline Costela suína & 9,00 & 0,74 & 9,74 & 11,30 & - & 1,56 & 13,84 \\
\hline Coxa s/coxa de frango & 3,45 & 0,74 & 4,19 & 4,78 & 0,33 & 0,26 & 5,44 \\
\hline Coxão de fora ou duro & 10,38 & 0,74 & 11,12 & 11,67 & - & 0,55 & 4,74 \\
\hline Coxão de dentro ou mole & 11,26 & 0,74 & 12,00 & 14,24 & - & 2,24 & 15,72 \\
\hline Coxinha da asa de & 4,80 & 0,74 & 5,54 & 5,95 & 0,42 & $(0,01)$ & $-0,16$ \\
\hline frango & 17,77 & 0,74 & 18,51 & 20,32 & - & 1,81 & 8,90 \\
\hline Filé mignon bovino & 5,39 & 0,74 & 6,13 & 7,38 & 0,52 & 0,73 & 9,89 \\
\hline Filé de peito de frango & 3,70 & 0,74 & 4,44 & 4,98 & 0,35 & 0,19 & 3,81 \\
\hline Frango colonial & 5,10 & 0,74 & 5,84 & 5,26 & - & $(0,58)$ & $-10,95$ \\
\hline Guisado bovino & 8,07 & 0,74 & 8,81 & 6,31 & - & $(2,50)$ & $-39,66$ \\
\hline & 14,84 & 0,74 & 15,58 & 16,68 & - & 1,10 & 6,59 \\
\hline Maminha bovina & 2,88 & 0,74 & 3,62 & 5,55 & - & 1,93 & 34,80 \\
\hline Miudos bovinos & 2,88 & 0,74 & 3,62 & 3,20 & - & $(0,42)$ & $-13,08$ \\
\hline Osso buço bovino & 7,84 & 0,74 & 8,58 & 6,93 & - & $(1,65)$ & $-23,81$ \\
\hline Paleta bovina & 10,57 & 0,74 & 11,31 & 14,27 & - & 2,96 & 20,73 \\
\hline Paleta ovina & 10,86 & 0,74 & 11,60 & 12,91 & - & 1,31 & 10,14 \\
\hline Patinho bovino & 3,47 & 0,74 & 4,21 & 4,94 & 0,35 & 0,38 & 7,69 \\
\hline Peito de frango & 10,57 & 0,74 & 11,31 & 14,27 & - & 2,96 & 20,73 \\
\hline Pernil ovino & 16,71 & 0,74 & 17,45 & 18,21 & - & 0,76 & 4,17 \\
\hline Picanha bovina & 5,41 & 0,74 & 6,15 & 4,78 & - & $(1,37)$ & $-28,66$ \\
\hline Ponta de peito bovino & 11,60 & 0,74 & 12,34 & 11,39 & - & $(0,95)$ & $-8,34$ \\
\hline Ponta da costela suína & 8,76 & 0,74 & 9,50 & 10,26 & - & 0,76 & 7,39 \\
\hline Ripa da chuleta bovina & 11,42 & 0,74 & 12,16 & 12,90 & - & 0,74 & 5,71 \\
\hline $\begin{array}{l}\text { Tatu lagarto bovino } \\
\text { Vazio bovino }\end{array}$ & 10,00 & 0,74 & 10,74 & 11,00 & - & 0,26 & 2,33 \\
\hline Total & 255,26 & 22,20 & 277,46 & 302,04 & 1,97 & 22,61 & 7,48 \\
\hline
\end{tabular}

Fonte: dados da pesquisa. 
Nota-se que houve variação tanto para mais como para menos no preço médio de venda dos produtos em relação ao mês anterior. Os produtos que tiveram margem bruta negativa no mês de outubro repetiram esse resultado no mês de novembro, com exceção da sobre coxa de frango e moela, não adquiridas nesse mês. Apresentaram margem bruta negativa também a coxinha da asa, o guisado bovino e a ponta da costela suína. A alcatra bovina apresentou maior rentabilidade entre os produtos vendidos no mês.

A Tabela 9 apresenta os custos totais dos produtos do açougue e a margem bruta no mês de dezembro de 2010. 
Gestão de custos no setor açougue de uma cooperativa de consumo. Andréa Oliveira da Silveira, Ana Paula Meneghetti Borges, Maria Dolores Pohlmann Velasquez

Tabela 9 - Custo total dos produtos do açougue e margem bruta no mês de dezembro/2010.

\begin{tabular}{|c|c|c|c|c|c|c|c|}
\hline \multirow[b]{2}{*}{ Produtos } & \multicolumn{3}{|c|}{ Custos (R\$) } & \multirow{2}{*}{$\begin{array}{l}\text { Preço de } \\
\text { venda (R\$) }\end{array}$} & \multirow{2}{*}{$\begin{array}{c}\text { Impostos } \\
(R \$)\end{array}$} & \multirow{2}{*}{$\begin{array}{l}\text { Resultado } \\
\text { bruto (R\$) }\end{array}$} & \multirow{2}{*}{$\begin{array}{l}\text { Margem } \\
\text { bruta \% }\end{array}$} \\
\hline & Compra & Outros & Totais & & & & \\
\hline Agulha bovina & 6,70 & 0,48 & 7,18 & 5,02 & - & $(2,16)$ & $-43,03$ \\
\hline Alcatra bovina & 12,84 & 0,48 & 13,32 & 17,64 & - & 4,32 & 24,50 \\
\hline Chester & 8,40 & 0,48 & 8,88 & 9,86 & 0,69 & 0,29 & 2,94 \\
\hline Chuleta bovina & 8,23 & 0,48 & 8,71 & 9,00 & - & 0,29 & 3,22 \\
\hline Costela janela bovina & 8,93 & 0,48 & 9,41 & 10,98 & - & 1,57 & 14,28 \\
\hline Costela minga bovina & 7,11 & 0,48 & 7,59 & 8,83 & - & 1,24 & 14,04 \\
\hline Costela ovina & 10,43 & 0,48 & 10,91 & 14,27 & - & 3,36 & 23,53 \\
\hline Costela suína & 10,28 & 0,48 & 10,76 & 11,10 & - & 0,34 & 3,06 \\
\hline Costela defumada suína & 14,50 & 0,48 & 14,98 & 20,47 & - & 5,49 & 26,83 \\
\hline Coxa s/coxa de frango & 3,57 & 0,48 & 4,05 & 4,72 & 0,33 & 0,34 & 7,19 \\
\hline Coxão de fora ou duro & 10,35 & 0,48 & 10,83 & 11,84 & - & 1,01 & 8,53 \\
\hline Coxão de dentro ou mole & 12,71 & 0,48 & 13,19 & 15,20 & - & 2,01 & 13,22 \\
\hline Coxinha da asa de frango & 5,10 & 0,48 & 5,58 & 5,98 & 0,42 & $(0,02)$ & $-0,33$ \\
\hline Coração de frango & 10,50 & 0,48 & 10,98 & 15,22 & 1,07 & 3,17 & 20,83 \\
\hline Filé mignon bovino & 25,31 & 0,48 & 25,79 & 27,38 & - & 1,59 & 5,81 \\
\hline Filé de peito de frango & 5,56 & 0,48 & 6,04 & 7,64 & 0,53 & 1,07 & 14,00 \\
\hline Frango colonial & 3,79 & 0,48 & 4,27 & 4,88 & 0,34 & 0,27 & 5,53 \\
\hline Frango Inteiro & 5,64 & 0,48 & 6,12 & 4,40 & 0,31 & $(2,03)$ & $-46,14$ \\
\hline Guisado bovino & 5,06 & 0,48 & 5,54 & 5,27 & - & $(0,27)$ & $-5,12$ \\
\hline Lingüiça de frango & 5,07 & 0,48 & 5,55 & 7,60 & - & 2,05 & 26,97 \\
\hline Lingüiça suína & 8,50 & 0,48 & 8,98 & 6,26 & - & $(2,72)$ & $-43,45$ \\
\hline Lombo suíno & 11,98 & 0,48 & 12,46 & 14,20 & - & 1,74 & 12,26 \\
\hline Maminha bovina & 16,23 & 0,48 & 16,71 & 17,95 & - & 1,24 & 6,90 \\
\hline Miúdos bovinos & 3,50 & 0,48 & 3,98 & 5,87 & - & 1,89 & 32,19 \\
\hline Osso buco bovino & 3,10 & 0,48 & 3,58 & 3,29 & - & $(0,29)$ & $-8,81$ \\
\hline Paleta bovina & 7,09 & 0,48 & 7,57 & 6,95 & - & $(0,62)$ & $-8,92$ \\
\hline Paleta ovina & 10,39 & 0,48 & 10,87 & 14,21 & - & 3,34 & 23,50 \\
\hline Patinho bovino & 10,56 & 0,48 & 11,04 & 13,22 & - & 2,18 & 16,49 \\
\hline Pé suíno & 3,50 & 0,48 & 3,98 & 6,29 & - & 2,31 & 36,72 \\
\hline Peito de frango & 3,70 & 0,48 & 4,18 & 4,92 & 0,34 & 0,39 & 8,13 \\
\hline Pele suína & 2,50 & 0,48 & 2,98 & 6,29 & - & 3,31 & 52,62 \\
\hline Peru temperado & 8,94 & 0,48 & 9,42 & 10,44 & - & 1,02 & 9,78 \\
\hline Pernil ovino & 10,39 & 0,48 & 10,87 & 14,21 & - & 3,34 & 23,50 \\
\hline Pernil suíno & 6,83 & 0,48 & 7,31 & 7,91 & - & 0,60 & 7,59 \\
\hline Picanha bovina & 19,10 & 0,48 & 19,58 & 20,54 & - & 0,96 & 4,68 \\
\hline Ponta de peito bovino & 5,06 & 0,48 & 5,54 & 4,96 & - & $(0,58)$ & $-11,69$ \\
\hline Rabo suíno & 5,90 & 0,48 & 6,38 & 6,29 & - & $(0,09)$ & $-1,43$ \\
\hline Ripa da chuleta bovina & 10,29 & 0,48 & 10,77 & 11,32 & - & 0,55 & 4,86 \\
\hline Sobre coxa de frango & 4,28 & 0,48 & 4,76 & 6,12 & 0,43 & 0,93 & 15,20 \\
\hline Tatu lagarto bovino & 11,96 & 0,48 & 12,44 & 12,72 & - & 0,28 & 2,20 \\
\hline Vazio bovino & 10,00 & 0,48 & 10,48 & 11,95 & - & 1,47 & 12,30 \\
\hline Total & 353,88 & 19,68 & 373,56 & 423,21 & 4,46 & 745,18 & 10,68 \\
\hline
\end{tabular}

Fonte: dados da pesquisa. 
Observa-se que os mesmos produtos que apresentaram margem bruta negativa nos meses anteriores mantiveram este resultado no mês de dezembro, com exceção da sobre coxa de frango, que neste mês teve um acréscimo relevante em sua margem bruta e da ponta da costela, que neste mês não foi adquirida. Além destes, o frango inteiro e o rabo suíno também apresentaram margem bruta negativa. $O$ produto de maior margem bruta positiva foi a pele suína, que não havia sido adquirido nos meses anteriores.

\section{CONCLUSÃO}

O objetivo geral do estudo foi determinar o custo dos produtos vendidos no açougue de uma cooperativa através do método de custeio por absorção e com a utilização do método do valor de mercado para apropriação dos custos conjuntos.

Ao se analisar a carne aviária e suína percebe-se que as primeiras apresentam pouca variação em seus custos médios enquanto que os custos das carnes suínas são oscilantes, ou seja, os valores variam conforme o tipo de produto.

O custo de compra dos cortes de carne ovina apresentou pouca variação entre os três meses analisados como também nos tipos de corte. $O$ fato deve-se aos preços de venda ter sido semelhantes em todo período. Por outro lado, o custo de compra da carne bovina variou tanto entre os meses como nos tipos de corte, ocasionado pela variedade de produtos e preços de venda diversificados. Quando analisados os demais custos, a parcela mais relevante refere-se à parte da mão de obra que não foi considerada na desossa dos produtos, tendo o mês de novembro novamente apresentado o maior custo.

No cálculo da margem, constatou-se que alguns produtos obtiveram margem bruta negativa nos três meses estudados, tais como: agulha bovina, lingüiça suína, osso buco bovino, paleta bovina e ponta de peito bovina. Outros produtos como: coxinha da asa e guisado também apresentaram margem bruta negativa, mas em apenas dois meses, enquanto que os produtos moela de frango, sobre coxa, ponta da 
Gestão de custos no setor açougue de uma cooperativa de consumo. Andréa Oliveira da Silveira, Ana Paula Meneghetti Borges, Maria Dolores Pohlmann Velasquez

costela suína, frango inteiro e rabo suíno apresentaram margem bruta negativa em apenas um mês.

No mês de outubro os produtos, agulha bovina e lingüiça suína tiveram um custo de compra maior que o preço de venda, isso sem considerar os outros custos já relacionados. Nos meses de novembro e dezembro, além desses dois produtos, também outros tiveram preços de venda inferiores ao valor de compra, a exemplo da paleta bovina e frango inteiro.

Isso revela que a cooperativa precisa rever a formação do preço de venda dos produtos do açougue para não incorrer em margens negativas que levam a diminuir o resultado da entidade. Também pode ocorrer de tais produtos serem vendidos abaixo do custo de compra por uma questão de estratégia de marketing, porém os administradores devem estar conscientes desses reflexos no resultado.

Pode-se verificar também que a cooperativa necessita de um controle mais efetivo na apuração dos custos por setor, pois não se identificou de forma precisa onde os materiais de higiene/limpeza/embalagem, energia elétrica e manutenção de máquinas e equipamentos são consumidos no interior da entidade.

Por fim, o estudo não finaliza os estudos sobre o tema em questão, considerando que o tema proposto pode ser discutido sob outros enfoques, contudo espera-se ter contribuído e difundido a questão do controle de custos não só no âmbito empresarial como também em entidades, como é o caso das cooperativas de consumo.

\section{REFERÊNCIAS}

BERNARDI, L. A. (1998). Política e formação de preços: uma abordagem competitiva sistêmica e integrada. (2 ed.). São Paulo: Atlas.

BERTÓ, D. J.; BEULKE, R. (2006). Gestão de custos. (1 ed.). São Paulo: Saraiva.

BEUREN, I. M. (Org.). (2008). Como elaborar trabalhos monográficos em contabilidade: teoria e prática. São Paulo: Atlas. 
Gestão de custos no setor açougue de uma cooperativa de consumo. Andréa Oliveira da Silveira, Ana Paula Meneghetti Borges, Maria Dolores Pohlmann Velasquez

CREPALDI, S. A. (2004).Curso básico de contabilidade de custos. (3 ed.). São Paulo: Atlas.

CRUZ, J. A. W. (2006). O Impacto do Custo do capital próprio no ponto de equilíbrio. Revista de Contabilidade do Mestrado em Ciências Contábeis da UERJ, Rio de Janeiro, v.11, n.1, p.12, jan./jun.

FONSECA, J. Z.; LINHARES, R. S. (2003). A Contabilidade de custos: Instrumento de vantagem competitiva. In: VIII Fórum de estudantes e profissionais de contabilidade do estado do Espírito Santo, Aracruz (ES). Anais em CD-ROM, 30 de out. a 01 de nov. 2003.

HANSEN, D. R.; MOWEN, M. M. (2001). Gestão de Custos. Contabilidade e Controle. (3 ed.). São Paulo, Thomson.

KOLIVER, O. (2009). Contabilidade de custos. (1 ed.). Curitiba: Juruá.

MARTINS, E. (2003). Contabilidade de Custos. (9 ed.). São Paulo: Atlas.

MINGATOS, J. (2011). Oportunidade. Revista Abastecimento. (27 ed.). p.60, mai/jun.

OLIVEIRA, L. M.; PEREZ JR., J. H. (2000). Contabilidade de Custos para não contadores. São Paulo: Atlas.

RIO GRANDE DO SUL. Lei Orgânica do ICMS №. 8.820 de 27 de janeiro de 1989. Institui o Imposto sobre Operações Relativas à Circulação de Mercadorias e Serviços e dá outras providências. Receita Estadual do Rio Grande do Sul, disponível em <http://www.legislacao.sefaz.rs.gov.br/Site/Document.aspx?inpKey=109360>. Acesso em 17/jun/2011.

SANTOS, J. (2005). Análise de Custos. Sistema de custeio marginal, relatórios e estudos de casos. (4 ed.). São Paulo: Atlas.

VIEIRA, E. P. (2008). Custos e formação do preço de venda. Revista Contabilidade e Informação da Unijuí, ed. 4, ljuí. Disponível em: < http://www.unijui.edu.br/component/option, com_wrapper2/ltemid,4047/lang,iso-88591/>. Acesso em: 26/ago/2010.

Data de Submissão:18/01/2012

Data de Aceite: 17/12/2012 